Trends in Mathematical Economics 
Alberto A. Pinto • Elvio Accinelli Gamba Athanasios N. Yannacopoulos

Carlos Hervés-Beloso

Editors

\section{Trends in Mathematical Economics}

Dialogues Between Southern Europe and Latin America

型 Springer 


\section{Editors}

Alberto A. Pinto

Matemática

Universidade do Porto

Porto, Grande Porto, Portugal

Athanasios N. Yannacopoulos

Statistics

Athens University Economics Business

Athens, Attiki, Greece

\author{
Elvio Accinelli Gamba \\ Economía \\ Universidad Autónoma de San Luis Potosi \\ San Luis Potosí \\ San Luis Potosí, Mexico \\ Carlos Hervés-Beloso \\ Ciencias Económicas y Empresariales \\ Universidade de Vigo \\ Vigo, Pontevedra, Spain
}

\section{ISBN 978-3-319-32541-5 \\ ISBN 978-3-319-32543-9 (eBook) \\ DOI 10.1007/978-3-319-32543-9}

Library of Congress Control Number: 2016944142

(C) Springer International Publishing Switzerland 2016

This work is subject to copyright. All rights are reserved by the Publisher, whether the whole or part of the material is concerned, specifically the rights of translation, reprinting, reuse of illustrations, recitation, broadcasting, reproduction on microfilms or in any other physical way, and transmission or information storage and retrieval, electronic adaptation, computer software, or by similar or dissimilar methodology now known or hereafter developed.

The use of general descriptive names, registered names, trademarks, service marks, etc. in this publication does not imply, even in the absence of a specific statement, that such names are exempt from the relevant protective laws and regulations and therefore free for general use.

The publisher, the authors and the editors are safe to assume that the advice and information in this book are believed to be true and accurate at the date of publication. Neither the publisher nor the authors or the editors give a warranty, express or implied, with respect to the material contained herein or for any errors or omissions that may have been made.

Printed on acid-free paper

This Springer imprint is published by Springer Nature

The registered company is Springer International Publishing AG Switzerland 
Alberto Adrego Pinto dedicates this volume to Maria Barreira Pinto

Elvio Accinelli dedicates this volume to Maria del Huerto Bettini 


\section{Preface}

This book includes selected papers that have been presented or discussed in the following conferences held in 2014: the 3rd International Conference Dynamics Games and Science III-DGS III, the 1st Hellenic-Portuguese Meeting on Mathematical Economics, AUEB, Athens, Greece, and XV Jornadas Latinoamericanas de Teoría Económica (JOLATE), Guanajuato, México.

The 3rd International Conference Dynamics Games and Science III-DGS III, on the occasion of the 50th birthday of Alberto A. Pinto, aims to bring together world top researchers and practitioners. DGS III represents an opportunity for MSc and $\mathrm{PhD}$ students and researchers to meet other specialists in their fields of knowledge and to discuss and develop new frameworks and ideas to further improve knowledge and science. DGS I was realized in 2008 at the University of Minho, in honor of Mauricio Peixoto and David Rand, and DGS II was realized in 2013 at the Calouste Gulbenkian Foundation, Lisbon.

The main purpose of the Hellenic-Portuguese Meeting on Mathematical Economics is to bring together researchers and students into a unique event to discuss and foster the spread of mathematical methods for game theory and economics in different countries particularly Portugal, Greece, and Spain. This meeting is organized every year and takes place in these countries looking to develop contacts and networks with Latin American researchers and students in the area of mathematical economics and game theory.

JOLATE is an annual meeting of the Latin American Association of Economics (ALTE). The main objective of ALTE is to provide a framework to promote and spread mathematical methods and research results in economic theory in Latin America. ALTE is involved in supporting activities related to economic theory at very different levels such as basic research, application, and education. The association has built up a Latin American network including universities and research centers in Argentina, Brazil, Chile, Colombia, Mexico, and Uruguay.

ALTE organizes the JOLATE meeting, a scientific conference that annually joins an increasing number of researchers and practitioners of mathematical economics methods, to contribute to the diffusion of their work and to the development of interactions between them to encourage potential future joint collaborations as well. 
JOLATE meetings have taken place in many different places in Latin American. The Universidad Nacional del Sur in Bahia Blanca, Argentina, organized the first one in 1999. Since then, other host universities were Universidad Nacional de San Luis (Argentina), Universidad de la República (Uruguay), Universidad Autónoma San Luis Potosí (México), Universidad de Chile (Chile), Instituto de Matemática Pura y Aplicada (IMPA, Brasil), Universidad EAFIT (Colombia), Universidad de los Andes (Colombia), and Centro de Investigaciones Matemáticas (CIMAT, México).

With this volume, the editors not only contribute to the advancement of research in these areas but also inspire other scholars around the globe to collaborate and research in these vibrant, emerging topics.

San Luis, Argentina

Alejandro Neme Jorge Oviedo 


\section{Acknowledgments}

The editors of this volume would like to thank all authors for their contributions which reflect the diversity of areas within mathematical economics developed, particularly, in Latin America and southern Europe. We also recognize the invaluable work of the reviewers whose comments and suggestions have largely benefited the edition of this volume.

We thank Robinson Nelson dos Santos, Associate Editor, Mathematics, SpringerVerlag, São Paulo, and Susan Westendorf, Project Coordinator, Springer Nature, for invaluable suggestions and advice and for assistance throughout this project.

Alberto Adrego Pinto would like to thank LIAAD INESC TEC and to acknowledge the financial support received by the ERDF (European Regional Development Fund) through the Operational Programme Competitiveness and Internationalization (COMPETE 2020) within project "POCI-01-0145-FEDER-006961" and by the national funds through the FCT (Fundação para a Ciência e a Tecnologia) (Portuguese Foundation for Science and Technology) as part of project UID/EEA/50014/2013 and within project "Dynamics, optimization and modelling" with reference PTDC/MAT-NAN/6890/2014. Alberto Adrego Pinto also acknowledges the financial support received through the Special Visiting Researcher Program [Bolsa Pesquisador Visitante Especial (PVE)] "Dynamics, Games and Applications" with reference 401068/2014-5 (call: MEC/MCTI/CAPES/CNPQ/FAPS), at IMPA, Brazil.

Elvio Accinelli acknowledges the financial support received through the project "Trends in Mathematical Economics Dynamics and Game Theory with Applications to the Economy," supported by the special program of CONACYT (México) "Estancias Sabática en el extranjero," with reference 264820, and through the project "Imitación, Bienestar, Crecimiento y Trampas de Pobreza," CONACYT with reference 167004.

Carlos Hervés-Beloso acknowledges the support by ECOBAS (Xunta de Galicia. Project AGRUP2015/08).

A. N. Yannacopoulos would like to thank Athens University of Economics and Business for its support of the meetings when they took place in Greece, as well as all the participants, who have honored us with their contributions to the meetings and this volume. 


\section{Contents}

1 Breaking the Circular Flow: A Dynamic Programming Approach to Schumpeter Martin Shubik and William D. Sudderth

2 A Review in Campaigns: Going Positive and Negative Grisel Ayllón Aragón

3 On Lattice and DA David Cantala

4 Externalities, Optimal Subsidy and Growth Enrique R. Casares and Horacio Sobarzo

5 The Fractal Nature of Bitcoin: Evidence from Wavelet Power Spectra

Rafael Delfin-Vidal and Guillermo Romero-Meléndez

6 Computing Greeks for Lévy Models: The Fourier Transform Approach

Federico De Olivera and Ernesto Mordecki

7 Marginal Pricing and Marginal Cost Pricing Equilibria in Economies with Externalities and Infinitely Many Commodities . Matías Fuentes

8 On Optimal Growth Under Uncertainty: Some Examples. Adriana Gama-Velázquez

9 Fundamental Principles of Modeling in Macroeconomics 163 Samuel Gil Martín 
10 Additional Properties of the Owen Value

Oliver Juarez-Romero, William Olvera-Lopez, and Francisco Sanchez-Sanchez

11 The Gödelian Foundations of Self-Reference, the Liar and Incompleteness: Arms Race in Complex Strategic Innovation... 217 Sheri Markose

12 Revenue Sharing in European Football Leagues:

A Theoretical Analysis

Bodil Olai Hansen and Mich Tvede

13 Weakened Transitive Rationality: Invariance of Numerical

Representations of Preferences.

Leobardo Plata

14 Symmetrical Core and Shapley Value of an Information

Transferal Game

Patricia Lucia Galdeano and Luis Guillermo Quintas

15 Marginal Contributions in Games with Externalities Joss Sánchez-Pérez

16 Approximation of Optimal Stopping Problems and Variational Inequalities Involving Multiple Scales in Economics and Finance

Andrianos E. Tsekrekos and Athanasios N. Yannacopoulos

17 Modelling the Uruguayan Debt Through Gaussians Models

Ernesto Mordecki and Andrés Sosa

18 A Q-Learning Approach for Investment Decisions Martín Varela, Omar Viera, and Franco Robledo

19 Relative Entropy Criterion and CAPM-Like Pricing Stylianos Z. Xanthopoulos

Erratum to: The Gödelian Foundations of Self-Reference, the Liar and Incompleteness: Arms Race in Complex Strategic Innovation 


\section{List of Contributors}

Grisel Ayllón Aragón Tecnologico de Monterrey, Mexico City, Mexico

David Cantala El Colegio de Mexico, Mexico City, Mexico

Enrique R. Casares Departamento de Economia, Universidad Autonoma Metropolitana Unidad Azcapotzalco, Mexico City, Mexico

Rafael Delfin-Vidal Departamento de Actuaría, Física y Matemáticas, Universidad de las Américas Puebla, Puebla, Mexico

Matías Fuentes Escuela de Economía y Negocios, Centro de Investigación en Economía Teórica y Matemática Aplicada, Universidad Nacional de San Martín, Buenos Aires, Argentina

Patricia Lucia Galdeano Facultad de Ciencias Físico Matemáticas y Naturales, Departamento de Matematicas, Universidad Nacional de San Luis, San Luis, Argentina

Adriana Gama-Velázquez El Colegio de México, Mexico City, Mexico

Bodil Olai Hansen Department of Economics, CBS, Frederiksberg, Denmark

Oliver Juarez-Romero CIMAT, Guanajuato, Gto., Mexico

Sheri Markose Economics Department, University of Essex, Colchester, UK

Samuel Gil Martin Facultad de Economia, Universidad Autónoma de San Luis Potosí, San Luis Potosi, Mexico

Ernesto Mordecki Mathematics Center, School of Sciences, Universidad de la República, Montevideo, Uruguay

Federico de Olivera Mathematics Center, School of Sciences, Universidad de la República, Montevideo, Uruguay

Departmento de Matemática, Federico Garcia Lorca entre Pastori y Goya, CeRP del Sur, Atlántida, Uruguay 
William Olvera-Lopez CIMAT, Jalisco S/N, Valenciana, C. P. 36240 Guanajuato, Guanajuato, Gto, México

San Luis Potosí, SLP, Mexico

Leobardo Plata UASLP, San Luis Potosí, SLP, Mexico

Luis Guillermo Quintas Facultad de Ciencias Físico Matemáticas y Naturales, Departamento de Matematicas, Universidad Nacional de San Luis, San Luis, Argentina

Departamento de Matematicas, IMASL (UNSL-CONICET), Universidad Nacional de San Luis, San Luis, Argentina

Franco Robledo Facultad de Ingeniería, Universidad de la República, Montevideo, Uruguay

Guillermo Romero-Meléndez Departamento de Actuaría, Física y Matemáticas, Universidad de las Américas Puebla, Puebla, Mexico

Joss Sánchez-Pérez Facultad de Economía, UASLP, San Luis Potosí, Mexico

Facultad de Economía, UASLP, Av. Pintores s/n, Col. B. del Estado, San Luis Potosí, Mexico

Francisco Sanchez-Sanchez CIMAT, Guanajuato, Gto., Mexico

Martin Shubik Department of Economics, Yale University, New Haven, CT, USA

Horacio Sobarzo El Colegio de Mexico, Centro de Estudios Economicos, Mexico City, Mexico

Andrés Sosa Mathematics Center, School of Sciences, Universidad de la República, Montevideo, Uruguay

William D. Sudderth School of Statistics, University of Minnesota, Minneapolis, MN, USA

Andrianos E. Tsekrekos Department of Accounting and Finance, School of Business, Athens University of Economics and Finance, Athens, Greece

Mich Tvede Newcastle University, Newcastle upon Tyne, Tyne and Wear, UK

Martín Varela Facultad de Ingeniería, Universidad de la República, Montevideo, Uruguay

Omar Viera Facultad de Ingeniería, Universidad de la República, Montevideo, Uruguay

Stylianos Z. Xanthopoulos Department of Mathematics, University of the Aegean, Karlovassi Samos, Greece

Athanasios N. Yannacopoulos Department of Statistics, School of Information Sciences and Technology, Athens University of Economics and Business, Athens, Greece 